\title{
CFRP 積層板の成形時熱変形に対する曲面成形板の影響
}

\author{
小山 昌志*，岡崎 宏康**，横 田 峰***，福 田 博* \\ (2008 年 3 月 7 日受付)
}

\begin{abstract}
Effect of Curved Mold for Thermal Deformation of CFRP Laminates
Masashi Koyama, ${ }^{*}$ Hiroyasu OKazAkI, ${ }^{* *}$ Takashi Yokota*** and Hiroshi FukudA*
\end{abstract}

(Received March 7, 2008)

Fiber reinforced plastics are often made by laminating unidirectional prepreg sheets in various directions. Large deformation during cure process of asymmetric CFRP is caused by mechanical and thermal anisotropic properties of unidirectional prepreg. Several reports have been released concerning flat mold processing. Experimental and FEM study on thermal deformation of orthogonal asymmetric laminates cured on curved mold have also been reported, although the area of survey was somewhat limited. In this paper, systematic experiments on thermal deformation of laminates were performed using flat and curved molds and some new findings were obtained.

\section{1. 緒言}

樹脂系複合材料では一方向プリプレグを色々な角度に 積層して成形することが多いが，一方向プリプレグは機 械的，熱的に大きな異方性をもつため，非対称積層をす ると大きな面外変形を生じることがある．この現象は古 くから知られており, Hyer の初期の報告1)でもすでに先 行研究のレビューがなされているほどである. Hyer ${ }^{1)}$ は まず各種積層構成の積層板を成形し，成形温度から常温 に戻したときの熱変形を観察・計測し，曲率，ねじり率

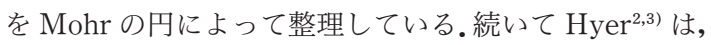
[0/90] 直交非対称積層板の熱変形を有限変形理論のも と，全ポテンシャルエネルギー最小の原理を用いて解析 した. 文献 2)では $\left[0_{2} / 90_{2}\right],\left[0_{4} / 90_{4}\right]$ の逆対称積層構成 について, 文献 3) では 4 層に限定し, たとえば $\left[0_{2} / 90 /\right.$ 0] といった積層構成も扱っている. Hamamoto ら ${ }^{4)}$ は Hyerの一連の研究を受けて, 変位の近似に改良をほど こし,また温度を変化させて変形形状を連続的に計測し, 成形温度まで戻すとほぼ元の形（平板）に戻ることを確

* 東京理科大学

Tokyo University of Science

**マツダ株式会社

MAZDA motor corporation

*** 東京理科大学大学院

Graduate Student, Tokyo University of Science
認するなど, [0/90] 逆対称積層板の理論をほぼ完成させ た. その後も Jun ら ${ }^{5)}$, 元木ら ${ }^{6)}, \mathrm{Cho} ら^{7)}$ などが, 成形 時の残留熱ひずみを導入した解析，コーナー部のめくれ 現象の解析, 型のあらさ（摩擦係数）が熱変形に及ぼす 影響の検討などを行っている。

以上の論文は Hyer の最初の論文 ${ }^{1)}$ を除き，[0/90] 直 交非対称積層平板を扱っている。一方 Fukuda ら ${ }^{8,9)}$ は [0/90] 逆対称積層板に広げて熱変形実験を行い, 変形後 の主曲率方向について Hyer ${ }^{1)}$ と異なった見解を提出し ている. Hyer ${ }^{2)}$ の流れを汲む解析および有限要素解析も 行っている.

文献 8）では曲面 (円筒形) 型上で成形した [0/90] 直 交非対称積層曲面板の熱変形実験結果も報告されてお り，曲面型を扱った初期のものであるが，現象論的段階 にとどまっている感はぬぐえない. Ren ら ${ }^{10)}$ は同じ課題 について FEM 解析を行い, いくつか興味ある結果を得 ている.

筆者らは引き続き, 曲面型上で成形した積層板の熱変 形実験を系統的に行い, いくつかの興味ある現象, 特に 新しい形のスナップスルー現象も見出したので, 報告す る.

$$
\text { 2. 方法 }
$$

\subsection{CFRP 積層材の作製}

本実験で用いた基材は, 旭化成工業社製の炭素繊維一 


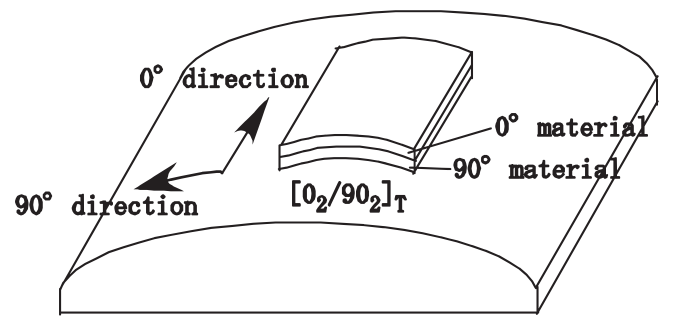

Fig. 1 Definition of angle on curved mold.

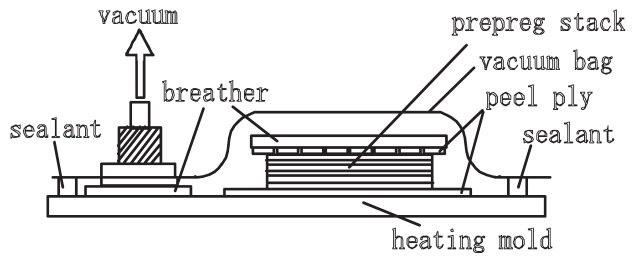

Fig. 2 Schematic illustration of forming method.

方向プリプレグ（AUT $125533 \mathrm{~A}$ 硬化温度 $180^{\circ} \mathrm{C}$ 厚さ $0.125 \mathrm{~mm}$ )である.このプリプレグを $100 \times 100 \mathrm{~mm}$ の寸 法に切り出し積層した. プリプレグの積層数を 4 枚に限 定し，積層構成は $0^{\circ}, 90^{\circ}$ の組み合わせで， $\left[0_{4}\right]_{\mathrm{T}},\left[0_{3} /\right.$ $\left.90_{1}\right]_{\mathrm{T}},\left[0_{2} / 90_{2}\right]_{\mathrm{T}},\left[0_{1} / 90_{3}\right]_{\mathrm{T}},\left[90_{4}\right]_{\mathrm{T}},\left[90_{3} / 0_{1}\right]_{\mathrm{T}},\left[90_{2} /\right.$ $\left.0_{2}\right]_{\mathrm{T}},\left[90_{1} / 0_{3}\right]_{\mathrm{T}}$ の全 8 種類とした. なお, 積層順序は上 から数えたものとした (Fig. 1参照).

また, 型の曲率が積層板の熱変形形状に与える影響を 調査するため, 成形に用いる型は, (1)平面型 (曲率 $0 \mathrm{~m}^{-1}$ ) (以後 RF), (2)部分円柱形曲面型 (曲率半径 $R=180 \mathrm{~mm}$ (曲率 $5.56 \mathrm{~m}^{-1}$ ) (以後 $\mathrm{R} 180$ )), (3)同上 (曲率半径 $R=450$ $\mathrm{mm}$ (曲率 $2.20 \mathrm{~m}^{-1}$ ) (以後 $\left.\mathrm{R} 450\right)$ ）の 3 種類のアルミ製 の型を用意した。なお，曲面型の上で成形した積層板は，

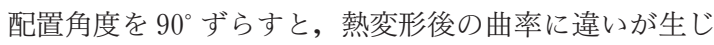
ることから, Fig. 1 に示すように, 円柱の長さ (母線) 方 向を積層材の $0^{\circ}$ 方向, 円筒の周方向を $90^{\circ}$ 方向と定義し て積層構成を区分した。

この各型上に作製したプリプレグスタックを乗せ，簡

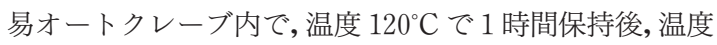
$180^{\circ} \mathrm{C}$, 圧力 $0.58 \mathrm{MPa}$ の条件下で加熱成形を行った。製 作数は, 各積層構成につき 2 枚ずつとした. 成形法には, Fig. 2 に示すように型の上に順次離型フィルム, プリプ レグスタック, ブリーザを重ね, ナイロンバッグで覆い 真空を引き，余分な樹脂をブリーザに吸収させるブリー

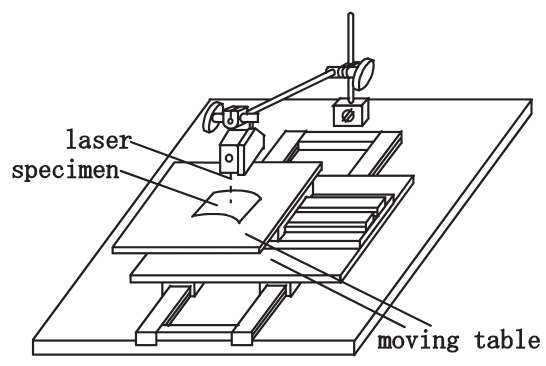

Fig. 3 Three-dimensional shape measurement device.

ド成形法を採用した。

\section{2 熱変形の形状測定}

成形した積層板の熱変形形状の測定は, Fig. 3 に示す 試料台の水平に対する試料変形量を測定するレーザ式変 位計を備えた 3 次元形状測定器を用いて行った. 測定点 は, 縦横 $10 \mathrm{~mm}$ 間隔で $64(8 \times 8)$ 点とした.

なお, 積層板の主曲率, 主曲率方向は, 本研究室で開 発したプログラムに形状測定で得られた值を代入して算 出した。

\section{3. 結果および考察}

\section{1 成形後の熱変形形状}

$\mathrm{RF}$ 上で成形した一方向材および R 180 上で成形した $\left[0_{1} / 90_{3}\right]$ 以外のすべての積層板において, Fig. 4 に示す 4 つの円筒形状 $(\mathrm{a})$ ～(d) のいずれかに属する熱変形を生 じた.ここで, Fig. 4 の各形状の説明をする.形状 (a)，(b) は上に凸の形状で，(a) は曲面型と同じ主曲率方向 $0^{\circ}$ を 有する形状である。形状 (b) は形状 (a)を法線周りに $90^{\circ}$ 回転した形状，すなわち主曲率方向を $90^{\circ}$ としももので ある. 形状 (c)，(d) は下に凸の形状で, 互いに主曲率方 向が $90^{\circ}$ 異なっている. 以後の結果, 考察の記述は, Fig. 4 の各形状 $(\mathrm{a})$ ～(d) を用いて行う.なお, 本実験の熱変形 形状は円筒形状であり, 主曲率の片方はほぼ $0^{\circ}$ であるの で, 今後主曲率および主曲率方向は, 主曲率の絶対值が 大きい方についてのみ取り扱うことにする。

唯一, R180 上で成形した $\left[0_{1} / 90_{3}\right]$ のみ, 積層構成が $0^{\circ}, 90^{\circ}$ の組み合わせにも関わらず円筒形状がねじれ主曲 率方向が $20^{\circ}$ ～ $25^{\circ}$ ずれた特異な形状となった.この挙動 については別途後述する.

\section{2 平面型 $(\mathrm{RF})$ 上で成形した積層板の変形挙動}

積層に偏りを持たせた積層板を RF 上で成形すると, 積層数の多い層の形状を維持する力が支配的となるた 
め, 積層数の少ない層の変形は打ち消され, 影響の大き

い繊維方向に曲がる変形挙動を示した。

また， $0^{\circ}$ 層と $90^{\circ}$ 層の積層数が同じである逆対象積層 板からは，2つの安定形状 (bs: before snap-through と as: after snap-through）を有するスナップスルー現象が 確認できた，スナップスルー現象では，凹凸が上下入れ

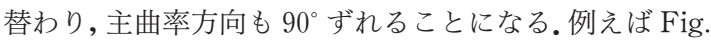
4 の（a）の形状をスナップスルーさせると，(d)の形状に なるということである。

\section{3 曲面型上で成形した積層板の変形挙動}

曲面型上 (R180, R450) の積層板の変形挙動は, 型の 影響を受け形状の曲率の大きさに違いが生じたが，基本 的には，RF上で成形した場合と同様に， $0^{\circ}$ 層と $90^{\circ}$ 層の 積層数が異なる場合, 積層数の多い層の変形が支配的と なった．また，スナップスルーが生じ，凹凹の上下が入

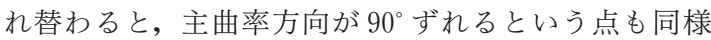
(Fig. 4 の (a)をスナップスルーさせると (d)の形状にな る) であった。

$\mathrm{R} 450$ 上のいずれの積層構成の積層板も, $\mathrm{RF}$ 上と同様 の変形挙動を呈した。

$\left[0_{3} / 90_{1}\right] ，\left[90_{3} / 0_{1}\right]$ は，RF 上で成形すると，下に凸 (Fig. 4 の (c), (d)) の形状に変形するが，このように下 に凸となる積層構成の積層板を曲面型上で成形する場合 の変形挙動は注意が必要であった。なぜなら, 曲面型の 曲率がある值以上になると，これらの積層構成の積層板 の成型後の変形形状は, 型の曲率が支配的となり, 上に 凸の形状へと変化することがあるためである.

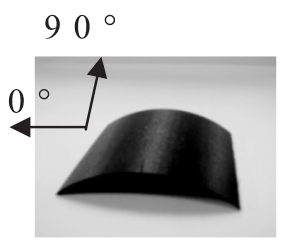

( a )

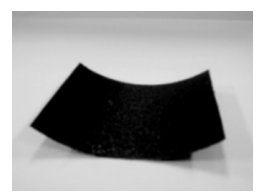

( C )

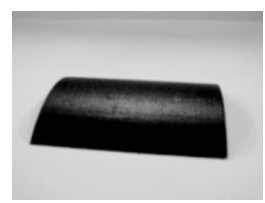

( b )

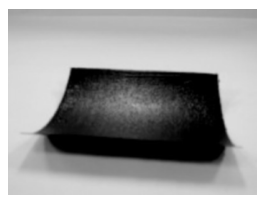

( d )
Fig. 4 Thermal deformation mode of CFRP laminates.
特に R180 上で成形した $\left[90_{3} / 0_{1}\right]$ においては興味深い 変形挙動を示した. その変形挙動とは, 積層板が曲面型 の影響によって強制的にスナップスルーさせられてお り，下に凸から上に凸へ，そして主曲率方向も拈よそ $90^{\circ}$

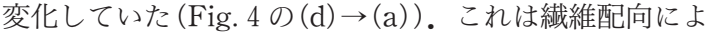
る下に凸の形状を維持する効果を，型の影響が超えたた めと考えられる。

また，曲面型は上に凸であることから，スナップスル 一現象を生じ 2 つ安定形状を有する逆対称積層板は, 上に凸の形状が優先的に現れる. 現に, R450上で成形し た逆対称積層板は，二つの安定形状を有しているのに対 し, R180 上で成形した逆対称積層板は上に凸の 1 形状し か現れなかった。

\section{4 曲面型の曲率が変形形状の主曲率に与える影響}

各型の上で成形した 2 枚の積層板の主曲率の結果の平 均を求めたものを Table 1 に示す.

曲面型上では，同じ積層構成でも積層角が $90^{\circ}$ 異なる と, 変形後の主曲率に差異が生じることが見て取れる。

Fig. 5 に一方向積層材の熱変形後の主曲率と型の曲率 の関係を示す、いずれの一方向材の主曲率も, 型の曲率 に比例するという結果が得られた。特に， $\left[90_{4}\right]_{\mathrm{T}}$ は曲面 型の影響を素直に受けており, 型の曲率と積層板の主曲 率の值が一致しているのが見て取れる。また，一方向材 の熱変形形状は，いずれも Fig. 4 の (a)の形状であった.

Fig. 6 に $90^{\circ}$ 層を 1 枚とした積層板の熱変形後の主曲 率と型の曲率の関係を示す。いずれの積層板も，一方向 材の結果と同様に, 主曲率の変化量と型の曲率が線形関 係にあり RF 上で成形した積層板の主曲率に曲面型の曲 率を足した值が，その曲面型の上で成形した積層板の主 曲率とほぼ一致するという結果が得られた。しかしこの 関係において, 曲面型の曲率が大きくなるにつれ, 誤差

Table 1 Principal curvature of each laminate.

\begin{tabular}{lccc}
\hline \hline Stack sequence & $\mathrm{RF}\left(\mathrm{m}^{-1}\right)$ & $\mathrm{R} 450\left(\mathrm{~m}^{-1}\right)$ & $\mathrm{R} 180\left(\mathrm{~m}^{-1}\right)$ \\
\hline$[0 / 0 / 0 / 0]$ & -0.21 & 1.76 & 4.85 \\
{$[0 / 0 / 0 / 90]$} & -13.8 & -11.3 & -7.2 \\
{$[0 / 0 / 90 / 90]$ bs } & -6.23 & -3.54 & - \\
{$[0 / 0 / 90 / 90]$ as } & 6.22 & 5.86 & 6.11 \\
{$[0 / 90 / 90 / 90]$} & 13.3 & 12.5 & 15.2 \\
{$[90 / 0 / 0 / 0]$} & 13.3 & 15.9 & 21.3 \\
{$[90 / 90 / 0 / 0]$ bs } & 6.22 & 8.81 & 12.0 \\
{$[90 / 90 / 0 / 0]$ as } & -6.32 & -5.92 & - \\
{$[90 / 90 / 90 / 0]$} & -13.8 & -14.8 & 6.99 \\
{$[90 / 90 / 90 / 90]$} & -0.21 & 2.13 & 5.38 \\
\hline
\end{tabular}




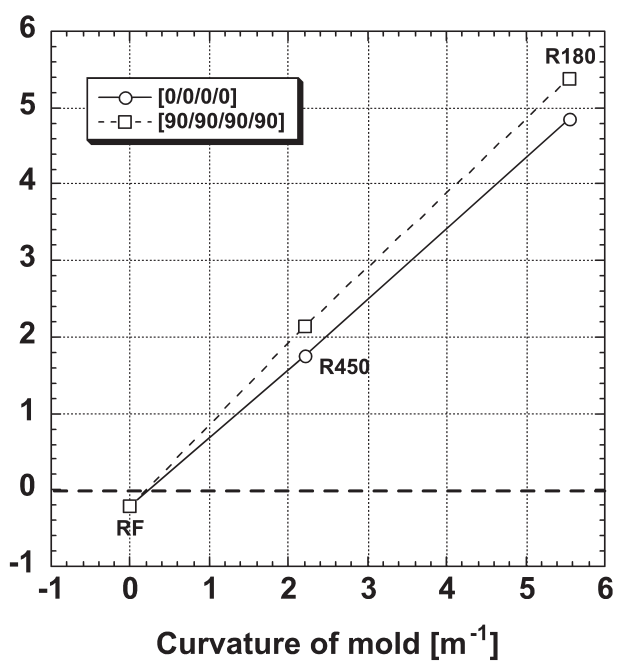

Fig. 5 Principal curvature of unidirectional laminates vs. curvature mold $(0 / 0 / 0 / 0 \& 90 /$ 90/90/90).
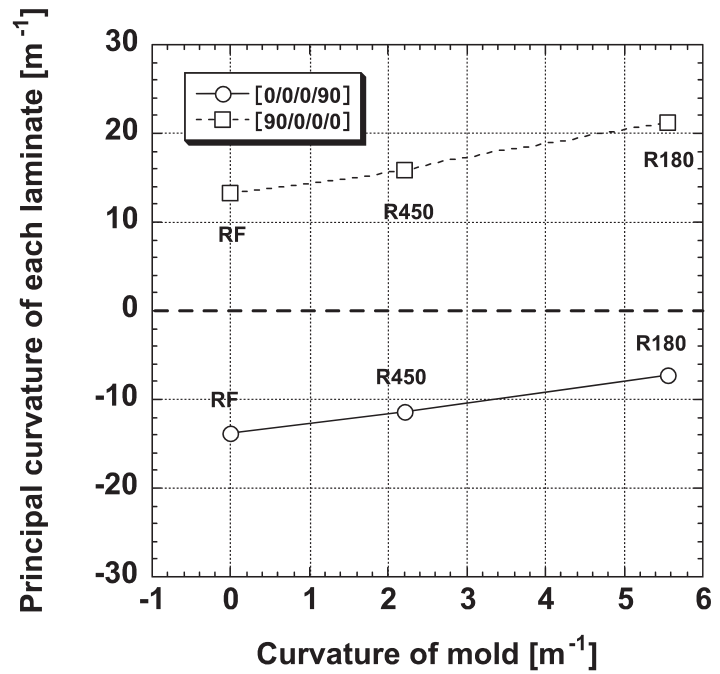

Fig. 6 Principal curvature of unidirectional laminates vs. curvature mold $(0 / 0 / 0 / 90 \& 90 /$ $0 / 0 / 0)$.

は少しずつ大きくなるという傾向がみられた。 $\left[0_{3} / 90_{1}\right]$ の熱変形形状は Fig. 4 の (a)， $\left[0_{1} / 90_{3}\right]$ の熱変形形状は Fig. 4 の(c)であった.

Fig. 7 に逆対称積層板の熱変形後の主曲率と型の曲率 の関係を示す。逆対称積層板はスナップスルー現象を生 じ, 2 つの安定形状を有するが, RF 上で成形した逆対称

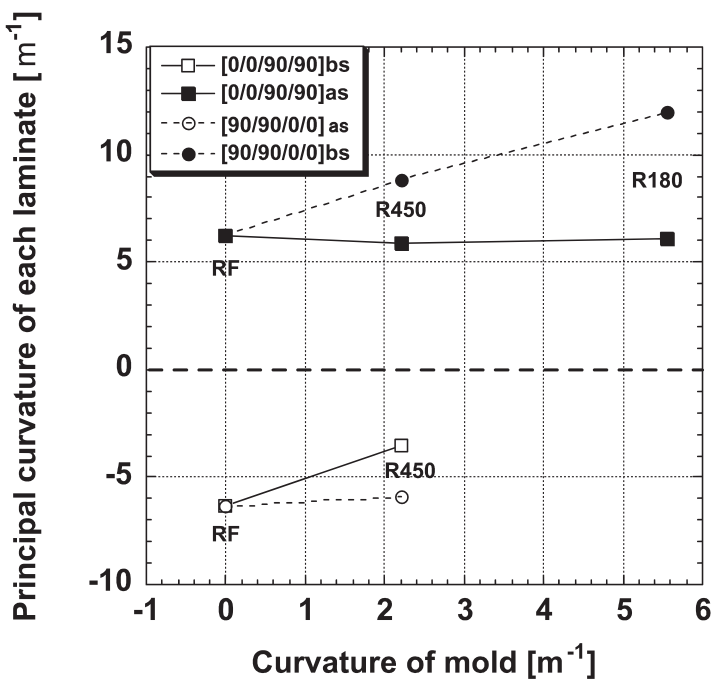

Fig. 7 Principal curvature of unidirectional laminates vs. curvature mold (bs: before snap-through, as: after snap-through $)(0 /$ $0 / 90 / 90 \& 90 / 90 / 0 / 0)$.

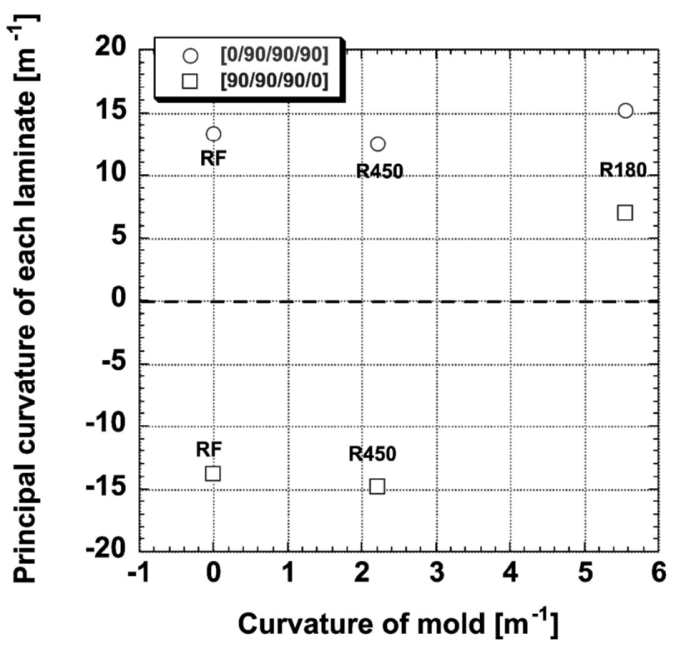

Fig. 8 Principal curvature of unidirectional laminates vs. curvature mold $(0 / 90 / 90 / 90$ \& 90/90/90/0).

積層板の二つの安定形状の主曲率を比較すると, 值がほ ぼ一致していることがわかる。本実験で用いた簡易オー トクレーブは Fig. 2 のように熱板(型)からの熱伝導に よりプリプレグを加熱する方式で, 板厚方向の温度分布 の影響が懸念されたが，Fig. 7 の RF の結果に見られる ように，温度分布の影響は無いものと推測できる。 


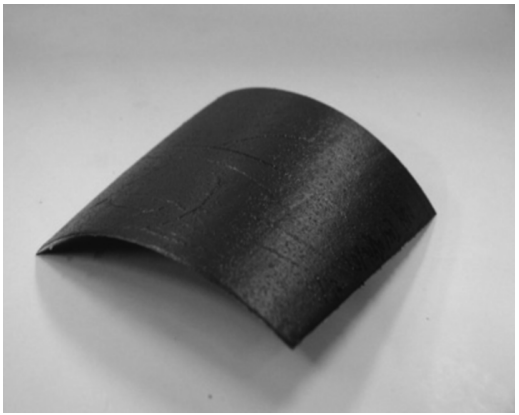

(a) Before Snap-through

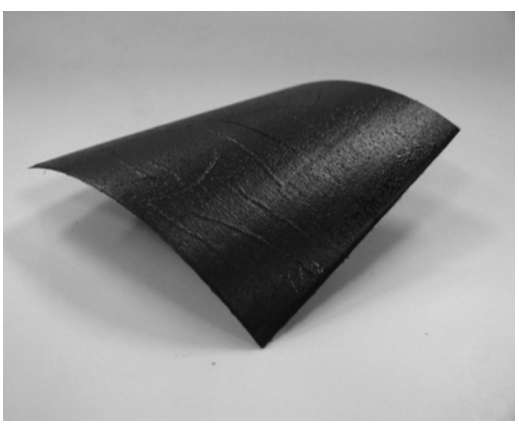

(b) After Snap-through

Fig. 9 Photographs after $\left[0_{1} / 90_{3}\right]$ was deformed.

スナップスルー現象は, $\mathrm{RF}$ および $\mathrm{R} 450$ の上で成形し た $\left[0_{2} / 90_{2}\right],\left[90_{2} / 0_{2}\right]$ で確認されたが，曲率の大きい $\mathrm{R} 180$ 上では生じなかった。これは, 型の曲率が大きくな るにつれその影響が支配的となり，2つの安定形状の主 曲率に差が生じ，やがて片方のモードしか現れなくなる ものと推測される.

$\left[90_{2} / 0_{2}\right]$ bs の熱変形形状は Fig. 4 の (c), $\left[0_{2} / 90_{2}\right]$ as の熱変形形状は Fig. 4 の(a)であり，その主曲率方向は いずれも, 曲面型の周方向 $\left(90^{\circ}\right.$ 方向 $)$ であった.これらの 積層板は，型の影響を素直に受け，その熱変形形状の主 曲率は, 型の曲率と比例関係を呈した。一方, $\left[90_{2} / 0_{2}\right]$ as の熱変形形状は Fig. 4 の (b), $\left[0_{2} / 90_{2}\right]$ bs の熱変形形状 は Fig. 4 の (d)であり, 熱変形後の主曲率方向は, いずれ も $0^{\circ}$ 方向であった。これらの積層板においては, 曲面型 の影響を素直に受けなかった。

以上のことから,一方向材や $\left[0_{3} / 90_{1}\right],\left[90_{2} / 0_{2}\right] \mathrm{bs}$ 等, 変形後の主曲率方向が, 曲面型の周方向となる $(\mathrm{RF}$ 上で は Fig. 4 の (a), (c)の形状となる) 積層構成の積層板を,
曲面型上で成形すると, 型の曲率の影響が支配的とな り, 型の曲率に比例した熱変形を生じるといえる。逆 に, $\left[0_{2} / 90_{2}\right]$ as, $\left[0_{1} / 90_{3}\right]$ 等, 熱変形後の主曲率方向が, $0^{\circ}$ 方向でかつ, 変形形状が上に凸となる $(\mathrm{RF}$ 上では Fig 4 の（b）の形状となる）積層構成の積層板を，曲面型上 で成形しても，曲面型の影響はあまり受けないと考えら れる.また, $\left[0_{3} / 90_{1}\right],\left[90_{3} / 0_{1}\right]$ 等, 変形形状が下に凸と なる (RF 上では Fig. 4 の (c), (d) の形状となる) 積層構 成の積層板を, 曲面型上で成形する場合は, 曲面型の曲 率によって, 変形形状の凸の向きが決定されると考えら れる。

\section{$3.5\left[0_{1} / \mathbf{9 0}_{3}\right]$ における特異变形形状}

R180 上で成形した $\left[0_{1} / 90_{3}\right]$ のみ，Fig. 9 に示すよう

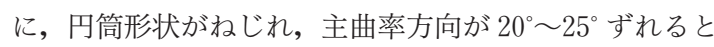
いう特異な形状を示した。ささらに本変形においては, 二 つの安定形状を有するスナップスルーも確認された。こ こでいうスナップスルーは，通常の上に凸から下に凸へ ととび移るものではなく Fig. 9 のように，上に凸のまま 主曲率方向がとび移るものである。この変形は， $0 \% 190$ の積層材では確認された報告は無く, 非常に興味深いも のであると考元れる. 本変形が生じた要因は, 積層材

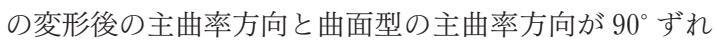
ており, かつ本来積層材に生じる変形の曲率の大きさ と，曲面型の曲率の大きさが近い值となることだと考え られる。変形が生じる際に熱変形による曲率と曲面型の 曲率の優位差が有る場合には，どちらかが支配的になり 前述している Fig. 4 (a)〜 (d) の円筒型となるが，互いの 曲率に優位差が生じない場合, 積層の際の積層角のずれ 等の何らかの影響を受け, 変形は Fig. 9 のように主曲率 方向がずれたものとなると考元れれ。本変形について は現在 FEM 解析を進めている。

\section{4. 結言}

・曲面型上で成形したクロスプライ積層板の変形形状 は一般に円筒形状で，成形時に曲率が受ける影響は，そ の積層構成によって異なることが確認された。

・R180 上で成形した $\left[0_{1} / 90_{3}\right]$ のみ円筒形状がねじ れ主曲率方向が $20^{\circ} \sim 25^{\circ}$ ずれた特異な形状が確認され， また，同時にスナップスルー現象も確認できた。この変 形についてはFEM 解析等により要因を明らかにしてい く必要があると考えられる。

\section{参 考 文 献}

1) M.W. Hyer:J. Compos. Mater., 15 (1981), 175- 
194.

2) M.W. Hyer: J. Compos. Mater., 15 (1981), 296310 .

3) M.W. Hyer:J. Compos. Mater., 16 (1982), 318340.

4) A. Hamamoto \& M.W. Hyer: Int. J. Solids Struct., 23, (1987) 919-935.

5) W.J. Jun \& C.S. Hong : Compos. Sci. Tech., 38 (1990), 55-67.

6) 元木信弥, 福田武人：材料，46 (1997), 349-353.
7) M. Cho, M.-H. Kim, H.S. Choi, C.H. Chung, K.-J. Ahn \& Y.S. Eom: J. Compos. Mater., 32 (1998), 460-482.

8) H. Fukuda, K. Takahashi \& S. Toda : Proc. ICCM-10, Whistler (1995), Vol. III, pp. 141-148.

9) H. Fukuda \& T. Kaneko: 1st Asia-Australasian Conference on Composite Materials, Osaka (1998), Vol. 1, pp. 307-1-307-4.

10) L. Ren \& A. Parvizi-Majidi : J. Compos. Mater., 37 (2003), 1801-1819. 